\title{
A trabalhadora no Brasil Mulher: análise das capas do 8 de março*
}

\author{
The female worker in Brasil Mulher: \\ analysis of covers from March 8th
}

\author{
Larissa Shayanna Ferreira Costa** \\ Verônica Soares da Costa***
}

\begin{abstract}
Resumo - O Brasil Mulher é um jornal feminista que surgiu em 1975 no bojo da resistência à ditadura militar. Posicionado à esquerda, se propõe a dialogar com mulheres da classe trabalhadora, na perspectiva de fortalecer a auto-organização e ampliar a consciência feminista. A pergunta central deste trabalho passa por como o jornal se apresenta a esse público e, na tentativa de sugerir respostas, faz-se uma análise das capas de duas edições que abordam o 8 de março, Dia Internacional das Mulheres. Mobilizando o método de análises de textos verbo-visuais sistematizado por Gonzalo Abril, as textualidades das capas são analisadas a partir das categorias de visualidade, mirada e imagem. Conclui-se que as capas selecionadas conformam textos verbo-visuais que representam um perfil da mulher trabalhadora brasileira que foge a estereótipos e que é capaz de disputar o imaginário do que é ser mulher na sociedade capitalista e patriarcal da década de 1970.
\end{abstract}

Palavras-chave: imprensa; feminismo; textualidades; Brasil Mulher.

\begin{abstract}
Brasil Mulher is a feminist newspaper founded in 1975 as part of the resistance movement against the military dictatorship. The liberal publication's stated purpose was to establish a dialogue among working-class women to strengthen self-organization and increase awareness of feminist ideology. This article aims to examine how the newspaper communicated with its audience through the analysis of two front covers published on March 8th, International Women's Day. Using analysis methods developed by Gonzalo Abril, a textual analysis was undertaken considering visual elements, perspective, and image. The selected front pages are visual texts which break from the stereotypical representations of working-class Brazilian women and challenge the idea of what it was to be a woman in the capitalist, patriarchal society of the 1970 s.

Keywords: press; feminism; textual analysis; Brasil Mulher.
\end{abstract}

\footnotetext{
* Artigo derivado do trabalho de conclusão de curso intitulado Imprensa e Feminismo: uma análise das capas do jornal Brasil Mulher e aprimorado para fins de publicação.

** Jornalista formada pela Universidade Federal de Minas Gerais, com pós-graduação em Estudos Latino-Americanos pela Universidade Federal de Juiz de Fora. E-mail: larissa.sfcosta@gmail.com. ORCID: https://orcid.org/0000-00026811-1853.

*** Jornalista do Programa de Comunicação Científica, Tecnológica e de Inovação da Fapemig. Mestre em História, Política e Bens Culturais pelo CPDOC/FGV, doutora em Comunicação Social pela UFMG. Professora na PUC Minas. E-mail:ve.scosta@gmail.com. ORCID: https://orcid.org/0000-0002-1324-0535.
} 


\section{Introdução}

O movimento de mulheres no Brasil vem sendo construído, desde o início do século XIX, com muitos embates, disputas, ganhos e perdas (VENTURI; GODINHO, 2013). Pautas feministas, como participação política, condições melhores e igualitárias de trabalho, autonomia em relação ao próprio corpo e combate à violência, caminham junto no país às reivindicações por direitos democráticos, humanos e trabalhistas.

Entender a trajetória do feminismo brasileiro é também passar pela história da relação das mulheres com a imprensa, pois, além da organização e das lutas de enfrentamento à opressão patriarcal, a propagação de ideias libertárias via jornais impressos foi, historicamente, uma tática adotada para a formação política e divulgação de novos valores e princípios de vida. Tanto a história das mulheres quanto a sua relação com a imprensa são temas ainda pouco debatidos na sociedade. Para Constância Lima Duarte (2003), a história do feminismo - e, pode-se acrescentar, a história da imprensa feminista - não é muito conhecida pelo fato de também não ser muito contada. A autora afirma que a bibliografia ainda é limitada, além de abordar de forma fragmentada os anos 1930 e a luta pelo voto, ou os anos 1970 e as conquistas mais recentes.

O jornal Brasil Mulher foi a primeira experiência de jornalismo feminista Pós-Golpe Militar de 1964. O tabloide de 16 páginas, construído e dirigido por mulheres militantes com experiência em partidos de esquerda, muitos deles clandestinos naquele período, circulou em diversos estados brasileiros até o ano de 1980, totalizando 20 edições, com periodicidade de dois meses ou mais. Além de informar e expor um ponto de vista feminista sobre a realidade da classe trabalhadora, o jornal cumpria com a função de ser instrumento de auto-organização das mulheres, de ampliação da consciência feminista e de fortalecimento da resistência à Ditadura Militar.

Inserido na segunda onda ${ }^{1}$ do movimento feminista internacional, que trouxe elaborações e práticas que colocaram a luta por direitos iguais em outro patamar, pode-se dizer que o Brasil Mulher se associou a uma vertente revolucionária do feminismo. Com a compreensão de que a emancipação das mulheres só é possível conjugada com a luta pelo fim da sociedade de classes, o jornal se destinava especificamente às mulheres trabaIhadoras, em sua diversidade: negras, operárias, moradoras de periferia etc.

Havia, portanto, uma abordagem de conteúdo que dialogava com a realidade dessas mulheres trabalhadoras. Eram comuns temas ligados ao sindicalismo, ao trabalho doméstico e de cuidados, a direitos sexuais e

\footnotetext{
1 O termo "segunda onda" é utilizado neste trabalho para designar o feminismo que emerge, sobretudo, após a década de 1960 nos Estados Unidos e Europa, reverberando para outros países do mundo. Não interessa para esta discussão o debate sobre a existência ou não de outras ondas posteriores à segunda, o que é objeto de debate de algumas autoras brasileiras.
} 
reprodutivos, direitos trabalhistas e creches. A construção visual do jornal indicava escolhas por uma estética que fugisse da lógica dos jornais e revistas empresariais, da manutenção de estereótipos, padrões de beleza e comportamentais. Nesse contexto, surge a questão que este trabalho pretende discutir: que estratégias textuais o jornal Brasil Mulher utiliza em suas capas para se apresentar ao seu público? Na perspectiva de sugerir respostas para essa questão, foram utilizadas, como metodologia de análise e fundamentação teórica, as discussões em torno do conceito de textualidades (LEAL et al., 2018) e das dimensões das verbo-visualidades (visualidade, mirada e imagem) elaboradas por Gonzalo Abril $(2007,2012)$ para a análise de duas capas do jornal.

Para fins de análise, a variedade de conteúdos publicados nas capas do jornal (textos, fotos, imagens variadas) é entendida como "não apenas um artefato semiótico (verbal, na maioria das vezes) encontrado no cotidiano, mas um composto necessariamente heterogêneo de signos, fortemente vinculado a uma dada situação comunicativa" (LEAL et al., 2018, p. 18). Ainda segundo o autor, "textualidade" é um conceito que passa a se referir tanto ao que faz "de um texto um texto" como aos modos de investigá-lo.

Já a metodologia de análise crítica de textos visuais de Gonzalo Abril (2007, p. 21) postula que "[...] da mesma forma que o silêncio do não-dito sempre age sobre o significado do que é dito, o invisível e o invisibilizado determinam o significado do que o texto visual dá a ver"2. Gonzalo Abril (2007) destaca ainda que a visualidade é como um espaço de pensamento cuja extensão do visual considera também a experiência de leitores e escritores de textos visuais. Para o autor, tais textos devem ser considerados formas fluentes e mutáveis no tempo da história e nos espaços da cultura, de modo que as observações de quem analisa são também carregadas por pressupostos de uma cultura visual, de um imaginário, de formas históricas de olhar. Essas categorias permitem observar, a partir do que é sensível e palpável, mas também do que é invisível, as relações de poder que sustentam a disputa de imaginários relacionados ao que é ser mulher na sociedade capitalista e patriarcal em uma data simbólica para a luta das mulheres: o 8 de março.

\section{Movimento de mulheres e resistência à Ditadura Militar}

No Brasil, o Golpe Militar de 1964 assassinou e sumiu com diversos militantes, jornalistas e guerrilheiros que ousaram criticar o regime totalitário. Mais de cinco décadas depois, muitos torturadores não foram punidos

\footnotetext{
${ }^{2}$ No original: "[...] del mismo modo que el silencio de lo no dicho actúa siempre sobre el sentido de lo que se dice, lo no visto y lo invisibilizado determinan el sentido de lo que el texto visual da a ver" (ABRIL, 2007, p. 21).
} 


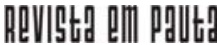

\} A TRABALHADORA - COSTA, L. S. F.; COSTA, V. S. \}

DOI: $10.12957 /$ rep.2021.56074

e muitos corpos estão desaparecidos. É nesse contexto de resistência que surge o Brasil Mulher, influenciado não somente pelas ideias e conflitos do movimento feminista internacional, mas também pelas experiências latinoamericanas, como a Revolução Cubana, em 1959.

Durante os anos 1970, as feministas brasileiras atuaram em movimentos auto-organizados de mulheres, em movimentos de luta pela terra ou por moradia, em partidos políticos, sindicatos, organizações clandestinas e grupos guerrilheiros. Nesse período, as mulheres das classes populares protagonizaram lutas que se referiam, conforme aponta Pedro Jacobi (1987), à defesa dos direitos mínimos de cidadania, às demandas em torno de carências de meios de consumo coletivo e à precariedade das condições reprodutivas cotidianas.

Nos bairros operários e com o apoio de paróquias progressistas, surgiram, nos anos de 1972 e 1973, os clubes de mães e associações de donas de casa, que lançaram o abaixo-assinado contra o custo de vida, movimento que, mais tarde, ficaria conhecido como Movimento do Custo de Vida. Esse foi considerado o primeiro movimento popular e de massas que ousou ir às ruas após o Ato Institucional no 5 (TELES; LEITE, 2013).

Por sua vez, algumas mulheres de classe média organizaram o Movimento Feminino pela Anistia, em 1975, que abrangia aquelas que também sofriam com os horrores da ditadura. A organização era liderada por Terezinha Zerbini, militante que havia sido presa política por apoiar o movimento estudantil e abrigar em sua casa políticos clandestinos. As muIheres que faziam parte do Movimento Feminino pela Anistia visitavam instituições, gabinetes de parlamentares, bem como personalidades do meio artístico e religioso para coletar assinaturas em favor da anistia. Nesse terreno nasceu o jornal Brasil Mulher, ideia da jornalista Joana Lopes, convidada por Terezinha Zerbini para participar do movimento.

Joana Maria Pedro (2006) destaca que o ano de 1975 foi um marco na história do movimento feminista brasileiro, uma vez que este retomou sua trajetória pública e pôde ampliar seu campo político de atuação. Esse ano foi considerado pela Organização das Nações Unidas (ONU) como o Ano Internacional da Mulher. Como parte das comemorações, no Brasil, foi realizada uma reunião de mulheres na Associação Brasileira de Imprensa $(\mathrm{ABI})$, no Rio de Janeiro. Em São Paulo, aconteceu o Encontro para o Diagnóstico da Mulher Paulista - evento patrocinado pelo Centro de Informação da ONU e pela Cúria Metropolitana -, liderado por mulheres do Partido Comunista Brasileiro ou próximas a ele (TELES; LEITE, 2013).

A intensificação do movimento de mulheres nesse período construiu um cenário de disputa sobre o que é ser mulher na sociedade e como resistir à Ditadura Militar. Os jornais feministas criados, inclusive o Brasil Mulher, passaram a ser porta-vozes desse movimento, divulgando agendas, conquistas e pautas, ao mesmo tempo em que serviam como ferramenta para organizar e aproximar mulheres. 


\section{Brasil Mulher: imprensa alternativa e feminista}

Segundo o projeto Memórias da Ditadura ${ }^{3}$, uma das primeiras ações do Golpe de 1964 foi o sufocamento da imprensa de esquerda, comunista, socialista e nacionalista. Jornais e revistas como Novos rumos, Semanário, A classe operária, Política operária, Ação popular e Movimento deixaram de circular imediatamente depois da tomada do poder pelos militares. No entanto, mesmo com todas as dificuldades, a esquerda brasileira manteve a imprensa clandestina e independente durante todo o período da Ditadura.

A imprensa independente pode ser incluída no conceito de Bernardo Kucinski (2003) de imprensa alternativa, incluindo inúmeros jornais que circularam durante os anos de Ditadura Militar no Brasil e se caracterizavam por noticiar os graves crimes praticados no país, como as mortes de presos políticos, as torturas, a violação de direitos humanos, além de pautas contra a censura e o regime autoritário. De acordo com Amelinha Teles e Rosalina Santa Cruz Leite (2013), a "questão da mulher" não era mencionada pela imprensa, uma vez que a repressão política era tanta que não havia "tempo nem espaço suficientes" para esse assunto.

O surgimento de jornais alternativos, em formato tabloide, que era um modelo mais barato, tornou-se um fenômeno incontrolável. Segundo o Memórias da Ditadura, mais de 150 publicações espalharam-se por todo o país. Além desses, diversos jornais, revistas, boletins, panfletos e cartazes eram produzidos por brasileiros exilados em países como França, Itália, Portugal e Estados Unidos. Os jornais, que muitas vezes tinham tiragem irregular e circulação restrita, eram expressão de oposição ao regime militar. Eram vendidos em bancas e, prioritariamente, comercializados mão a mão pelos próprios militantes em eventos ou nas sedes das organizações (LEITE, 2003).

O jornal Brasil Mulher teve a sua edição número zero publicada em 9 de outubro de 1975. Esse jornal foi o primeiro dirigido às mulheres e elaborado por mulheres no período pós-guerrilhas, entre o ano de 1975 e 1980. Afirmar que os jornais são feitos por mulheres significa dizer que são elas que compõem os conselhos editoriais, além de serem as responsáveis pela direção política, linha editorial e redação das principais reportagens. Isso não quer dizer que havia uma exclusão da colaboração masculina, o que pode ser visto, por exemplo, nas capas das primeiras edições, que contaram com fotos de Chico Resende (LEITE, 2003).

\footnotetext{
${ }^{3}$ O portal Memórias da Ditadura, lançado em dezembro de 2014, tem o objetivo de divulgar a história brasileira durante o período dos governos militares compreendidos entre 1964 e 1985. A iniciativa foi realizada pelo Instituto Vladimir Herzog em resposta a uma demanda da Secretaria de Direitos Humanos da Presidência da República. Pode ser visitado em www.memoriasdaditadura.org.br. Acesso em: 6 mar. 2020.
} 


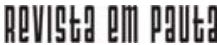

\} A TRABALHADORA - COSTA, L. S. F.; COSTA, V. S. \}

DOI: $10.12957 /$ rep.2021.56074

Até 1980, foram 17 edições regulares e mais três denominadas "extras". Com tiragem de $5 \mathrm{mil}$, mas que chegou a 10 mil exemplares em algumas edições, o Brasil Mulher era distribuído, em diversos estados brasileiros, de forma voluntária pelas próprias mulheres que escreviam os textos e faziam as edições e por militantes apoiadores da iniciativa. O primeiro exemplar do Brasil Mulher foi editado em Londrina, no Paraná, e transportado para São Paulo. A avaliação, na época, era que a capital paulista permitia maior divulgação e, consequentemente, poderia ampliar a adesão ao movimento pela anistia. Em novembro de 1975, a sede do jornal já havia mudado para a capital paulista, onde vivia Terezinha Zerbini. Em sua casa, ela chegou a abrigar as primeiras reuniões para discussão e elaboração das pautas.

O Brasil Mulher, assim como outras publicações da imprensa alternativa, não possuía patrocínio ou publicidade, o que causou uma situação financeira precária durante toda a sua existência. A manutenção da publicação dependia da contribuição mensal das mulheres que faziam parte da equipe. Em várias edições, havia um apelo aos leitores para que também contribuíssem financeiramente e divulgassem o jornal.

A estrutura básica do Brasil Mulher contava com quatro editorias principais que foram, em sua maioria, fixas durante toda a existência do jornal. O editorial trazia textos opinativos sobre a condição das mulheres na sociedade, na maioria das vezes, vinculada a outros temas políticos. A editoria anistia contava com entrevistas, reportagens, textos e notícias sobre o tema e a campanha pelo perdão a presos e perseguidos políticos. Os fatos estão aí era uma seção composta, geralmente, ou por uma entrevista sobre questões conjunturais de interesse das mulheres, ou por pequenas notas sobre o movimento feminista. Por último, a editoria denominada arte comunicação; educação; rosa dos ventos era composta por matérias e notícias sobre acontecimentos internacionais de interesse das mulheres.

O Brasil Mulher, assim como outros jornais feministas da época, reunia em sua equipe mulheres de esquerda, muitas egressas de prisões políticas. Pode-se dizer que o jornal era uma ferramenta de trabalho de base com as mulheres e de divulgação do feminismo, uma vez que grande parte da distribuição era realizada nas periferias. As militantes iam para os bairros, liam e debatiam as matérias junto com as mulheres e transformavam esses momentos de "construção de um feminismo popular, contra a ditadura e comprometido com a luta de classes" (TELES; LEITE, 2013, p. 67). 


\section{As mulheres nas capas do Brasil Mulher}

Das 20 edições do Brasil Mulher ${ }^{4}, 13$ capas apresentam fotos ${ }^{5}$ de mulheres em primeiro plano, duas demonstram somente silhuetas ${ }^{6}$, três capas têm montagens ou desenhos ${ }^{7}$ e duas capas possuem fotos de manifestações mistas $^{8}$, mostrando homens e mulheres. Para este trabalho, optouse por descrever as duas capas (Figura 1 e Figura 2) das edições especiais do Brasil Mulher, uma de abril de 1977 e a outra de março de 1980, que têm em comum, além das fotografias, o tema sobre o 8 de março, Dia Internacional de Luta das Mulheres.

Metodologicamente, este trabalho compreende a capa como um texto visual culturalmente inserido, a partir das concepções de cultura visual desenvolvidas por Gonzalo Abril (2012). Para Vanessa Costa Trindade (2016), a abordagem do texto visual proposta por Abril permite que as capas sejam lidas contextualmente e interpretadas reflexiva e discursivamente. Assim, é possível dar conta das instituições e dimensões técnicas que influenciaram a produção do jornal, bem como discutir o produto - no caso, o Brasil Mulher, a partir de seus efeitos no contexto histórico e dos discursos produzidos aos seus possíveis destinatários.

As capas do jornal, entendidas também como porta de entrada para o conteúdo do miolo, mediam processos comunicativos, que, como reforça Bruno Leal et al. (2018), são textualidades que emergem com relações amplas e diversas, capazes de conectar passado e expectativas de futuro. Tal abordagem é relevante, considerando que se busca uma análise cultural e historicamente situada em relação à publicação e circulação desses jornais no contexto na ditadura brasileira, conforme já apresentado. Essa perspectiva permite considerar também uma noção de texto em que o visual é tão importante quanto o verbal. Assim, as capas têm a capacidade de convocar o público pelas fotografias, pelas chamadas das matérias e reportagens, pelo design e pelas cores (TRINDADE, 2015).

Gonzalo Abril (2012) propõe a análise do texto visual a partir de três dimensões: a visualidade, que envolve as qualidades sensíveis e variáveis perceptíveis; a imagem, que evoca a representação de imaginários; e a mirada, que aponta para os sujeitos, o espaço e o tempo do discurso. É importante destacar que essa diferenciação é uma maneira didática, uma vez que estão em constante diálogo, se misturando em uma relação complexa.

Do aspecto da visualidade, que envolve a "trama visual", o conjunto de significantes visuais, que conformam o texto visual e constroem

\footnotetext{
${ }_{4}^{4}$ Para este trabalho, as edições digitalizadas do Brasil Mulher foram cedidas, gentilmente, pelo Instituto Vladimir Herzog. Algumas edições podem ser visualizadas na Hemeroteca Digital da Biblioteca Nacional, em http://bndigital. bn.gov.br/hemeroteca-digital/. Acesso em: 6 mar. 2020.

${ }^{5}$ As edições regulares 0,1 , 2, 3, 5, 6, 7, 8, 9, 15, 16 e as edições extras de abril de 1977 e de 8 de março de 1980.

${ }^{6}$ As edições de número 4 e 13.

${ }^{7}$ As edições regulares 10 e 11 e a edição extra de março de 1979.

${ }^{8}$ As edições regulares 12 e 14.
} 


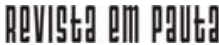

\} A TRABALHADORA - COSTA, L. S. F.; COSTA, V. S. \}

DOI: $10.12957 /$ rep.2021.56074

sua coerência, inclui características como cor, textura, forma e composição. Além disso, para Gonzalo Abril (2012), a visualidade é também composta pelo invisível, por aquilo que foi reprimido ou tido como pressuposto. Para o autor, visual, que é o "o que se vê", relaciona-se sempre com aquilo que não se vê, "com distintos fenômenos que não pertencem propriamente ao reino do visível, mas sem os quais seríamos cegos à imagem, não veríamos nada, ou veríamos sem ver" (ABRIL, 2012, p. 21 - tradução livre) ${ }^{9}$. Ou seja, o visível engloba dimensões não mostradas, mas que têm efeitos diretos e tornam o que se vê cheio de sentido.

Do ponto de vista da visualidade, as fotografias estampadas nas duas capas do Brasil Mulher estão em preto e branco e apresentam fotos de mulheres com características de quem pertence à classe trabalhadora: vestem roupas simples; têm o cabelo preso, que parece algo prático; e não estão maquiadas (Figuras 1 e 2).

\section{Figura 1 - Capa da edição extra de 1977 do Brasil Mulher}

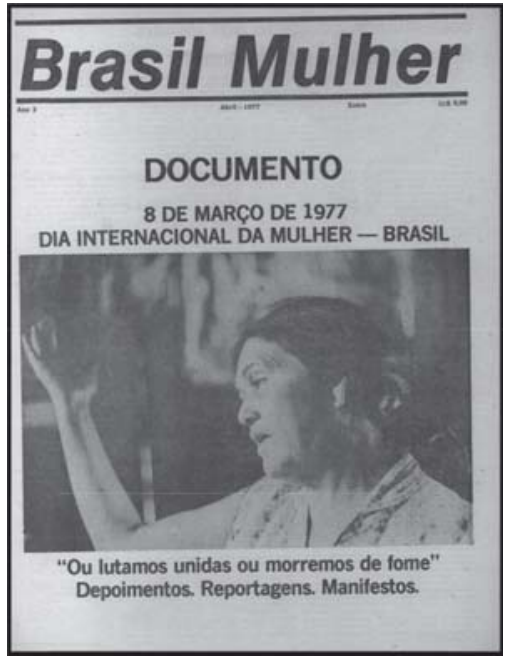

Fonte: Instituto Vladimir Herzog

Aparentemente, as mulheres fotografadas não se prepararam para as fotos e não fazem poses, mas foram clicadas em afazeres cotidianos, uma delas em um discurso (Figura 1) e outra no local de trabalho (Figura 2). Sobre a impressão em preto e branco, possivelmente há relação com o custo, uma vez que o jornal passou por desafios financeiros e a impressão colorida é mais cara.

\footnotetext{
9 "Lo visual, 'lo que se ve', se relaciona siempre con lo que no se ve, con distintos fenómenos que no pertenecen propiamente al reino de lo visible, pero sin los cuales seríamos ciegos a la imagen, no veríamos nada, o veríamos sin ver. Así que no hablamos de la relación de lo visible con lo invisible sin más, sino con ciertos fenómenos que no siendo propiamente visibles tienen efectos en lo que se ve, es decir, en el sentido de lo que se ve" (ABRIL, 2012, p. 21).
} 


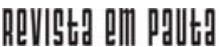

\} A TRABALHADORA - COSTA, L. S. F.; COSTA, V. S. \}

DOI: $10.12957 /$ rep.2021.56074

A capa da edição de 1977 (Figura 1) apresenta uma mulher de meia idade, com rugas aparentes, que parece falar algo. Abaixo da foto, a chamada principal está entre aspas "Ou lutamos unidas ou morremos de fome", título da matéria principal da edição que narra uma atividade realizada pelos movimentos de mulheres no 8 de março daquele ano, em São Paulo. Nessa reunião, cerca de 600 mulheres de bairros periféricos, operárias e representantes de clubes de mães, deram depoimentos sobre suas condições de vida.

A frase escolhida para a manchete é de dona Olga, do Sindicato dos Trabalhadores das Indústrias Têxteis, que, em seu depoimento, conta que trabalha em casa seis horas por dia, além das oito horas da jornada na fábrica e mais duas horas que perde dentro do ônibus. O que chama a atenção é a convocação que o jornal faz às mulheres a se organizarem como única saída para a transformação da realidade. Essa edição é apresentada como um documento que reúne depoimentos, reportagens e manifestos de diversas mulheres brasileiras.

Já a edição de 1980 (Figura 2) apresenta somente uma fotografia, que ocupa a página inteira. É uma mulher jovem que manuseia um tear, indicando que é uma operária de alguma indústria da tecelagem. Sem chamadas ou textos para além da logomarca do Brasil Mulher, a capa inova e apresenta o símbolo do feminismo, no canto inferior direito, o que demarca o posicionamento político da edição. O símbolo do feminismo é utilizado até hoje como representação do movimento, dos ideais políticos e da necessidade de pautar a igualdade entre homens e mulheres na sociedade.

Ainda que não seja objetivo deste artigo estender a análise para as textualidades internas ao jornal, cabe indicar que, além do símbolo do

Figura 2 - Capa do especial 8 de março de 1980 do Brasil Mulher

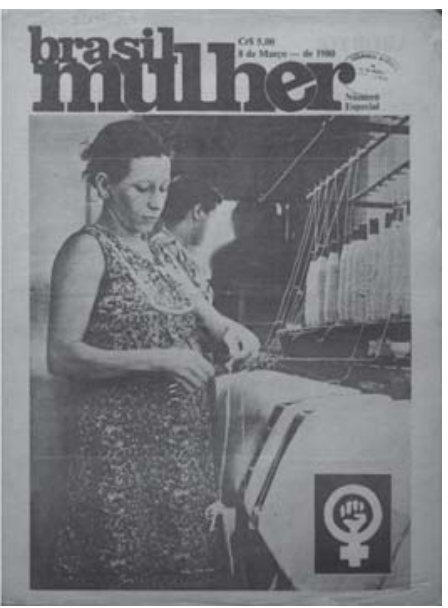

Fonte: Hemeroteca Digital da Biblioteca Nacional 
feminismo, a edição de 1980 traz na segunda página uma matéria sobre o aborto como um direito das mulheres, assunto até hoje travado com tabu na sociedade brasileira. Outros temas, que ainda são pautas do movimento feminista contemporâneo, como creches, participação sindical, auto-organização e trabalho doméstico e de cuidados, são abordados ao longo do jornal, demonstrando que a mulher da capa expressa a trabalhadora brasileira, que assume diversas funções ao mesmo tempo e que possui seus direitos negados.

Do ponto de vista da mirada, os textos visuais existem porque alguém os olha em um lugar e tempo determinados, no contexto de uma prática discursiva, como aponta Abril (2012). O sujeito que olha para o texto visual recebe e processa o conteúdo a partir de sua experiência e concepções criadas de dentro de sua cultura, inclusive considerando relações de dominação, exploração e poder.

Analisar as capas sob essa perspectiva envolve entender o que há de relações de poder no contexto daquela sociedade, mas, sobretudo, busca compreender o que há de construção de resistência imersa no texto visual. Como já mencionado, o jornal Brasil Mulher foi ferramenta de construção do feminismo, numa perspectiva de resistência à Ditadura Militar. Esse feminismo se alinha à luta das mulheres que, historicamente, enfrentam o sistema capitalista e o patriarcado como forma de construir uma sociedade mais igualitária para homens e para mulheres.

A abordagem das trabalhadoras nas capas que tratam do Dia Internacional de Luta das Mulheres indica que o protagonismo da luta deve ser daquelas que têm seus direitos negados, sejam trabalhistas, sexuais ou reprodutivos. É possível deduzir, por meio das capas, que o 8 de março é uma proposta organizativa concreta que possibilita a transformação da vida das mulheres.

Em sua análise, Juliana Segato Tamião (2009) afirma que, para as militantes do jornal Brasil Mulher, as bases teóricas para compreender a opressão feminina deveriam seguir as categorias e ferramentas marxistas. Assim, não fazia sentido analisar a condição das mulheres desvinculadas do modo de produção capitalista e suas relações de exploração. Esse elemento colocado pela autora é interessante para reforçar a ideia de que o jornal construía um feminismo com projeto estratégico de transformação da realidade. A perspectiva, portanto, de que a emancipação feminina é inseparável da emancipação humana - e da construção de uma sociedade justa e igualitária - aparece como elemento constituinte do texto visual das capas analisadas do jornal (Figuras 1 e 2).

Além disso, tal aspecto se reforça porque o Brasil Mulher se preocupa em expor sua perspectiva ideológica com a visibilidade das demandas das "mulheres reais", nos termos de Rachel Moreno (2013). Para essa autora, a mídia empresarial não se preocupa, até os dias de hoje, em divulgar as mobilizações, as datas importantes para as mulheres, pelo contrário, há um processo de criminalização e ridicularização. Na mídia comercial, "fal- 


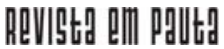

\} A TRABALHADORA - COSTA, L. S. F.; COSTA, V. S.

DOI: $10.12957 /$ rep.2021.56074

tam a problemática e a realidade atuais. Faltam a diversidade e o contraditório" (MORENO, 2013, p. 103).

Apesar de as capas analisadas neste artigo trazerem mulheres bran$\mathrm{Cas}^{10}$, é importante dizer que outras edições possuem fotografias de mulheres negras em destaque. Elas aparecem em situações cotidianas, inclusive em espaços organizativos do feminismo, como o caso da edição 15. A foto dessa edição é uma mulher do povo, com pano na cabeça, que faz um discurso no $1^{\circ}$ Congresso da Mulher Paulista, evento que marcou o movimento feminista da década de 1970. As mulheres das capas extras sobre o 8 de março são brancas e operárias, o que possibilita a reflexão sobre o fato de as mulheres negras, ainda hoje, mas, principalmente, à época da circulação do jornal, serem maioria das desempregadas e no trabalho informal.

Em relação à construção de imaginários, cabe apontar alguns elementos sobre a representação das mulheres na mídia, uma vez que isso está relacionada com a construção histórica de imaginários sociais sobre a figura da mulher e seu lugar na sociedade. A imagem, conforme Gonzalo Abril (2012), não é algo obrigatoriamente visual, mas também o que é da ordem do experimentável, que faz das imagens parte e resultado da construção de imaginários sociais. Vanessa Costa Trindade (2016) sintetiza que as imagens atuam na criação de algum sentido de realidade, de algo compartilhado.

A mídia contribui diretamente na construção do que é ser mulher na sociedade, o que, obviamente, evoca e reproduz relações de poder intrínsecas ao patriarcado, ao racismo e ao capitalismo. As representações de beleza, felicidade e comportamentos valorizados em uma sociedade desigual são veiculadas por meio de propagandas, seleção de ícones que viram celebridades, de heroínas e vilãs das novelas e até de brinquedos femininos, como a boneca Barbie. Para Rachel Moreno (2013), todo esse conteúdo vai sendo introjetado nas mulheres como um modelo aspiracional, que influencia fortemente a formação da subjetividade feminina.

Pesquisa desenvolvida em 2010, pela Fundação Perseu Abramo em parceria com o Sesc, denominada Mulheres brasileiras e gênero nos espaços público e privado investigou, entre outras temáticas, a representação das mulheres na mídia. A amostra era composta de 2.365 mulheres urbanas e rurais, com mais de 15 anos, distribuídas em 25 estados brasileiros. Entre os resultados que interessam para este trabalho, Heloisa Buarque de Almeida (2013) aponta que é notável como, no geral, as mulheres não gostam da forma como são retratadas pela mídia, principalmente a televisão.

Esse assunto do padrão de beleza pode estar relacionado com o nível de insatisfação das mulheres com seu próprio corpo. Conforme dados

\footnotetext{
${ }^{10} \mathrm{O}$ processo de construção e identificação de cor e raça no Brasil é complexo e exige considerar questões de autoidentificação e fatores fenotípicos. Opta-se aqui por afirmar que as imagens das capas analisadas representam muIheres brancas. No entanto, é importante ressaltar que, a depender de quem olha, as fotografias também podem representar mulheres pardas.
} 


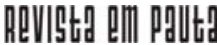

\} A TRABALHADORA - COSTA, L. S. F.; COSTA, V. S. \}

DOI: $10.12957 /$ rep.2021.56074

apresentados nessa pesquisa, $47 \%$ não estão satisfeitas com sua aparência e $29 \%$ não estão felizes com seu peso ou com sua barriga, o que mostra a influência do padrão de magreza como sendo considerado o que é bonito.

Outra pesquisa citada por Rachel Moreno (2013), que responde ao que as brasileiras declaram ver quando estão diante do espelho, apresenta resultados semelhantes: $100 \%$ das mulheres declaram ver "uma pessoa nada sexy"; 98\%, "uma imagem pouco bonita"; 91\% vê uma "pessoa estressada"; e $51 \%$ afirma que é "alguém que precisa de plástica". Além disso, dois terços das mulheres no mundo, de 15 a 60 anos, evitam atividades cotidianas porque se sentem mal com sua aparência.

Os dados mostram que o imaginário do que é ser mulher na sociedade é algo impossível para a maior parte da população e que as muIheres consideram tal retrato nocivo ao seu reconhecimento. Quem se beneficia com isso é a indústria de cosméticos, que disponibiliza no mercado uma parafernália de produtos e procedimentos cada vez mais invasivos, como lipoaspiração, cirurgias plásticas etc. Essa discussão de como a mídia trata as mulheres não é nova, inclusive, foi tema abordado pelo jornal Brasil Mulher em texto denominado A mulher nos jornais, publicado na edição n. 9, de 1977. Esse texto apresenta uma pesquisa realizada por um grupo de sete jornalistas de Brasília que, durante um mês, analisaram a frequência com que as mulheres apareciam no noticiário de oito jornais brasileiros e o tipo de tratamento que Ihes era oferecido.

\section{Considerações finais}

O jornal Brasil Mulher se associa ao feminismo socialista, que, historicamente, começa a ser construído pelas mulheres europeias no final do século XIX e início do XX. O que garante essa afirmação é que o jornal defende um feminismo baseado na formação política, uma vez que o conteúdo era utilizado pelas militantes como material de estudo junto com as mulheres das periferias; baseado na organização popular, não só porque as militantes jornalistas participavam de partidos clandestinos de esquerda, mas porque havia um incentivo à organização das mulheres em sindicatos, clubes de mães, associações de bairros etc.

Um terceiro aspecto que aponta para um feminismo socialista é a existência de um projeto político para sociedade, que envolve a destruição das diversas formas de opressão e exploração. De imediato, o feminismo que emergiu (no Brasil Mulher e também em outros jornais feministas) sentiu necessidade de manter um vínculo orgânico com o movimento de muIheres trabalhadoras da cidade e do campo.

O público do jornal, portanto, são as mulheres trabalhadoras. Não por acaso, o conteúdo da publicação trazia, prioritariamente, reflexões 
sobre o cotidiano desses sujeitos, como a sua subordinação aos homens na casa, no trabalho e na política.

Sem a pretensão de exaurir o debate, mas de sugerir uma resposta à pergunta inicial deste trabalho, que passa pela forma como o Brasil Mulher se apresenta por meio de suas capas, indo ao público em que pretende chegar, pode-se dizer que é através da representação da mulher trabaIhadora, capaz de disputar o imaginário do que é ser mulher na sociedade brasileira. Há uma fuga aos estereótipos e aos padrões de beleza reproduzidos pela mídia empresarial, hegemônica na sociedade, ao mesmo tempo em que se estimula a discussão da necessidade da organização das mulheres.

A imprensa feminista teve papel fundamental na construção de um feminismo brasileiro com cara própria. Os jornais, como o Brasil Mulher, impulsionaram a criação de diversos espaços autônomos organizativos nos anos iniciais da década de 1980. De acordo com levantamento apresentado por Amelinha Teles e Rosalina Santa Cruz Leite (2013), nessa época havia mais de 150 grupos de mulheres no país.

Nesse sentido, compreender a história da imprensa feminista é importante para entender a história do feminismo brasileiro, suas conquistas, seus avanços e recuos. Resgatar a história das mulheres, por sua vez, é imprescindível para qualquer um que se propõe a entender, de fato, a história do Brasil. Sobretudo, para aquelas pessoas que buscam a transformação da realidade rumo a uma sociedade justa e igualitária, em que as mulheres gozem plenamente sua liberdade. 


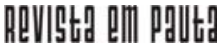

\} A TRABALHADORA - COSTA, L. S. F.; COSTA, V. S. \}

DOI: $10.12957 /$ rep.2021.56074

\section{Referências}

ABRIL, G. Análisis crítico de textos visuales: mirar lo que nos mira. Madrid: Editorial Sintesis, 2007.

ABRIL, G. Tres dimensiones del texto y de la cultura visual. Revista Científica de Información y Comunicación. 2012. Disponível em: https://goo.gl/ kHxTpn. Acesso em: 1 mar. 2020.

ALMEIDA, H. B. de. As mulheres e as imagens da televisão. In. VENTURI, G.; GODINHO, T. (Org.). Mulheres brasileiras e gênero nos espaços público e privado: uma década de mudança na opinião pública. São Paulo: Editora Perseu Abramo, 2013.

DUARTE, C. L. Feminismo e literatura no Brasil. Estudos Avançados, São Paulo, v. 17, n. 49, set./dez. 2003. Disponível em: https://goo.gl/fUxtK6. Acesso em: 1 mar. 2020.

JACOBI, P. Movimentos sociais urbanos no Brasil: reflexão sobre a literatura nos anos 70 e 80. BIB, Rio de Janeiro, n. 23, 1987.

KUCINSKI, B. Jornalistas e revolucionários: nos tempos da imprensa alternativa. São Paulo: Edusp, 2003.

LEAL, B. et al. (Org.). Textualidades midiáticas. Belo Horizonte: PPGCom/ UFMG, 2018.

LEITE, R. de S. C. Brasil mulher e Nós mulheres: origens da imprensa feminista brasileira. Estudos Feministas, Florianópolis, v. 11, n. 1, jan./jun. 2003. Disponível em: https://goo.gl/m9h8iG. Acesso em: 7 mar. 2020.

MORENO, R. A mulher e a mídia. In: VENTURI, G.; GODINHO, T. (Org.). Mulheres brasileiras e gênero nos espaços público e privado: uma década de mudança na opinião pública. São Paulo: Editora Perseu Abramo, 2013. PEDRO, J. M. Narrativas fundadoras do feminismo: poderes e conflitos (1970-1978). Revista Brasileira de História, São Paulo, v. 26. n. 52, dez. 2006. Disponível em: https://goo.gl/ufaEQx. Acesso em: 7 mar. 2020.

TAMIÃO, J. S. Escritas feministas: os jornais Brasil mulher, Nós mulheres, e Mulherio (1975-1988). Dissertação (Mestrado em História Social). Pontifícia Universidade Católica de São Paulo, São Paulo, 2009.

TELES, A.; LEITE, R. de S. C. Da guerrilha à imprensa feminista: a construção do feminismo pós-luta armada no Brasil (1975-1980). São Paulo: Editora Intermeios, 2013.

TRINDADE, V. C. O aborto na revista feminina: o tratamento do tema nas capas da Tpm em 2005 e 2014. In. JURNO, A. C. et al. (Org). Disputas e alteridades: diálogos possíveis na mídia contemporânea. Belo Horizonte: FAFICH/UFMG, 2016. 


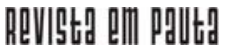

\} A TRABALHADORA - COSTA, L. S. F.; COSTA, V.S. \}

DOI: $10.12957 /$ rep.2021.56074

VENTURI, G.; GODINHO, T. Igualdade de gênero: avanços, estagnações e recuos. In. VENTURI, G.; GODINHO, T. (Org.). Mulheres brasileiras e gênero nos espaços público e privado: uma década de mudança na opinião pública. São Paulo: Editora Perseu Abramo, 2013.

DOI: $10.12957 /$ rep.2021.56074

Recebido em 08 de março de 2020.

Aprovado para publicação em 10 de abril de 2020.

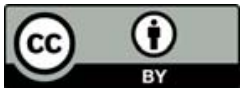

A Revista Em Pauta: Teoria Social e Realidade Contemporânea está licenciada com uma Licença Creative Commons Atribuição 4.0 Internacional. 